\title{
Real-Time Observation of High-Temperature Gas Corrosion in Dry and Wet $\mathrm{SO}_{2}$-Containing Atmosphere
}

\author{
FLORIAN FALK,${ }^{1,2,5}$ MARTINA MENNEKEN ${ }^{3}$ and \\ CHRISTIANE STEPHAN-SCHERB ${ }^{10}{ }^{1,4}$
}

\begin{abstract}
1.-Bundesanstalt für Materialforschung und -prüfung (BAM), Unter den Eichen 87, 12205 Berlin, Germany. 2.-Faculty III - Prozesswissenschaften, Technical University Berlin, Berlin, Germany. 3.-Steinmann Institute of Geology, Mineralogy and Paleontology, University of Bonn, Bonn, Germany. 4.-Fachbereich Geowissenschaften, Freie Universität Berlin, Malteserstraße 74-100, 12249 Berlin, Germany. 5.—e-mail: florian.falk@bam.de
\end{abstract}

Sulfur and water have a fundamental impact on the corrosion rate and potential failure of materials. It is therefore necessary to understand the mechanisms, rates, and potential means of transport, as well as the reactions of these elements with an alloy. This paper investigates the effect of water vapor in the initial stages of $\mathrm{SO}_{2}$ corrosion of an Fe-9Cr-0.5Mn model alloy at $650^{\circ} \mathrm{C}$ in situ under laboratory conditions using energy-dispersive x-ray diffraction analysis. Two separate experiments were run, one with a $99.5 \%$ $\mathrm{Ar}+0.5 \% \mathrm{SO}_{2}$ atmosphere and one with a $69.5 \% \mathrm{Ar}+0.5 \% \mathrm{SO}_{2}+30 \% \mathrm{H}_{2} \mathrm{O}$ atmosphere. With a wet atmosphere, the alloy formed a scale with decreasing oxygen content towards the scale-alloy interface. Sulfides were identified above and below a $(\mathrm{Fe}, \mathrm{Cr})_{3} \mathrm{O}_{4}$ layer in the inner corrosion zone. In contrast to this, the overall scale growth was slower in a dry $\mathrm{SO}_{2}$ atmosphere.

\section{INTRODUCTION}

Ferritic-martensitic high-temperature alloys are state-of-the-art materials used for superheater tubes in coal-, biomass-, or cofired power plants. ${ }^{1,2}$ The pipe materials P23, P91, P92, and VM12SH contain a minimum of $2 \%$ to $13 \% \mathrm{Cr}$ by weight ${ }^{3}$ to support the formation of protective Cr-rich oxide layers. Combustion of various fuels produces reactive gas atmospheres containing high amounts of $\mathrm{CO}_{2}, \mathrm{SO}_{2}, \mathrm{H}_{2} \mathrm{O}, \mathrm{NO}_{x}$, and $\mathrm{O}_{2}$, being responsible for substantial corrosion on the fire side of the pipe. $\mathrm{SO}_{2}$ in particular is a prominent cause of catastrophic application failure. ${ }^{4-6}$ The formation of an inner sulfide layer under an oxide scale causes the scale to spall easily. ${ }^{7}$ Huczkowski et al. ${ }^{8}$ reported presence of $(\mathrm{Fe}, \mathrm{Cr}$ )-sulfides after investigation of $\mathrm{P} 92$ aged at $550^{\circ} \mathrm{C}$ in an $\mathrm{Ar} / \mathrm{H}_{2} \mathrm{O} / \mathrm{SO}_{2}$ gas atmosphere. The earlystage nucleation and growth processes of corrosioncausing metal sulfides at the scale-metal interface are currently not well understood. Furthermore, the harmful effect of water vapor at 1 bar on $\mathrm{Fe}-\mathrm{Cr}$ alloys causes catastrophic breakaway oxidation of protective chromia $\left(\mathrm{Cr}_{2} \mathrm{O}_{3}\right)$ scales. ${ }^{9}$ Energy-dispersive $\mathrm{x}$-ray diffraction (EDXRD) has been shown to be a powerful tool to follow the oxidation and sulfidation processes of materials at high temperatures in real time. ${ }^{10,11}$ Based on this, the current work investigates the very early stages of oxidation and sulfidation of a ferritic 9 wt.\% Cr-containing model alloy in $\mathrm{SO}_{2} / \mathrm{H}_{2} \mathrm{O}$ and $\mathrm{SO}_{2}$ atmospheres.

\section{EXPERIMENTAL PROCEDURES}

\section{Materials and Experimental Boundary Conditions}

Model alloy sheets were cold rolled to thickness of $3 \mathrm{~mm}$ and heat treated in an Ar atmosphere for $8 \mathrm{~h}$ at $800^{\circ} \mathrm{C}$ by the manufacturer. The alloy composition, determined by means of optical emission spectroscopy (OES), was $9.2 \% \mathrm{Cr}, 0.48 \% \mathrm{Mn}$ by weight (balance $\mathrm{Fe}$ ). To generate a defined coupon surface, $40 \mathrm{~mm} \times 25 \mathrm{~mm}$ samples were metallographically ground and surface finished with $1 \mu \mathrm{m}$ particle size diamond polish. Ageing experiments were performed on the model alloys in a high-temperature radiationheated reactor developed for combining EDXRD with high-temperature corrosion. ${ }^{10}$

Before each EDXRD ageing experiment, a reactor purge and rinse cycle using only argon gas was 
performed to minimize its oxygen contamination. Heating to the experimental temperature $T_{2}=650^{\circ} \mathrm{C}$ was conducted under pure argon flow of $200 \mathrm{ml} / \mathrm{min}$ (ALPHAGAZ $^{\mathrm{TM}} 2$ by Air Liquide). A thermocouple inside the specimen and another next to it were used to control the temperature during both experiments. Data acquisition was done by defining $t_{0}$ as the starting time of collecting 1 pattern/min at only $\mathrm{Ar}$ gas flow. After $5 \mathrm{~min}, t_{5}$ was reached and $1 \mathrm{ml} / \mathrm{min}$ $\mathrm{SO}_{2}$ was released into the radiation heater. Another experiment was performed by introducing $0.06 \mathrm{ml} /$ min $\mathrm{H}_{2} \mathrm{O}$ into the gas mixture just before the $\mathrm{Ar} / \mathrm{SO}_{2}$ gas entered the reaction chamber. The gas compositions, given here in vol. $\%$, were $99.5 \% \mathrm{Ar}+0.5 \% \mathrm{SO}_{2}$ in the dry experiment and $69.5 \% \mathrm{Ar}+0.5 \% \mathrm{SO}_{2}+$ $\sim 30 \% \mathrm{H}_{2} \mathrm{O}$ in the wet experiment. The incoming synchrotron white x-ray beam hit the sample surface at $3^{\circ}$, holding a constant focal plane during the whole experiments.

Reflection line positions to identify reaction products were calculated theoretically using Inorganic Crystal Structure Database (ICSD) data ${ }^{12}$ and the energy-dispersive Bragg equation. ${ }^{10}$ The experimental routine is illustrated in supplementary Fig. S1, and general information about the instrumentation and the major setup at the Energy-Dispersive Diffraction (EDDI) beamline are listed in Ref. ${ }^{13}$.

After the experiments, surface changes caused by the corrosion process were comprehensively characterized. Phase analysis was performed by XRD. The corroded alloys were prepared by embedding the samples in transparent epoxy resin. Cross-sections were prepared in the area where the synchrotron $\mathrm{x}$ ray beam hit the sample during the experiment with silicon carbide paper from P120 to P1200, and subsequently finished with $1 \mu \mathrm{m}$ diamond paste. Microstructural and chemical analyses were performed by scanning electron microscopy (SEM; LEO Gemini 1530). Additional phase characterization was carried out using a Horiba ISA Dilor LabRAM confocal Raman spectrometer with confocal length of $300 \mathrm{~mm}$ in the Department of Mineralogy at Freie Universität Berlin. References were taken from the RRUFF database. ${ }^{14}$

\section{RESULTS}

\section{In Situ Ageing Experiments and Postcharacterization}

Figure $1 \mathrm{~b}$ and $\mathrm{c}$ shows the time-resolved diffraction pattern of both experiments. Reflections of $\alpha$ ferrite and oxides/sulfides can be distinguished. The intensity of the $\alpha$-ferrite $(110 \mathrm{keV}$ to $57.7 \mathrm{keV})$ reflection decreased with ageing time. A more pronounced decrease was observed in the dry experiment. Furthermore, introduction of $\mathrm{SO}_{2}$ into the reactor was followed by simultaneous formation of magnetite $\left(\mathrm{Fe}_{3} \mathrm{O}_{4}\right)(311 \mathrm{keV}$ to $46 \mathrm{keV})$ and $(\mathrm{Fe}$, Cr)-sulfides (144 keV to $55.8 \mathrm{keV})$. After $20 \mathrm{~min}$, hematite $\left(\mathrm{Fe}_{2} \mathrm{O}_{3}\right)$-related reflections at $43.7 \mathrm{keV}$ and $53.1 \mathrm{keV}$ were clearly observed. After $10 \mathrm{~h}$ of reaction, the reflection at $46 \mathrm{keV}$ exhibited a strongly asymmetric peak shape, indicating coexistence of $\mathrm{Fe}_{3} \mathrm{O}_{4}$ and $(\mathrm{Fe}, \mathrm{Cr})_{3} \mathrm{O}_{4}$. The integrated intensities of reflections of the reaction products and $\alpha$-ferrite were extracted by fitting using a Gaussian function. The peak area of the reaction products as a function of time increased constantly (Fig. 1d).

The reaction sequence for corrosion product formation changed significantly under wet conditions. As shown in Fig. 1c, phase reflections of magnetite and ( $\mathrm{Fe}, \mathrm{Cr}$ )-sulfides were observed at $46.3 \mathrm{keV}$ and $55.8 \mathrm{keV}$ after introducing the corrosive gas into the chamber. Furthermore, after $110 \mathrm{~min}$ of reaction, the 200 reflections of wüstite $(\mathrm{FeO})(54.4 \mathrm{keV})$ could be seen.

The oxide reaction products as observed by EDXRD could be confirmed by laboratory XRD analysis (Supplementary Fig. S2). Further analysis of the reaction products after the ageing process was performed by microscopic characterization.

\section{Scale Phases and Morphology}

Figure 2 shows representative regions of the scales grown on $\mathrm{Fe}-9 \mathrm{Cr}-0.5 \mathrm{Mn}$ after ageing in a dry (a) and wet (b) $\mathrm{SO}_{2}$-containing atmosphere. Next to the elemental distribution of $\mathrm{Fe}, \mathrm{Mn}, \mathrm{Cr}, \mathrm{O}$, and $\mathrm{S}$, the secondary-electron (SE) image highlights the scale architecture.

In both experiments, an outer and an inner corrosion zone can be distinguished. It is shown that the outer zone mainly consisted of $\mathrm{Fe}$-oxides, whereas the inner zone consisted of $\mathrm{Fe}-\mathrm{Cr}$-oxides. In addition, sulfur accumulated primarily at the interface of the inner and outer corrosion zone and in the inner corrosion zone, but to different extents when comparing the results in the dry and wet atmosphere.

The scale formed in the dry experiment was inhomogeneous and contained cavities and buckling reaction products at the scale-gas interface. Inside the model alloy, some grain boundaries were $\mathrm{Cr}$ depleted and local $\mathrm{Cr}$-oxides formed. The distribution of $\mathrm{Fe}$ and $\mathrm{O}$ indicates that $\mathrm{Fe}_{2} \mathrm{O}_{3}$, which was identified by EDXRD and XRD, could be found at the gasscale interface and $\mathrm{Fe}_{3} \mathrm{O}_{4}$ beneath. Sulfur was only detected in the inner corrosion zone. The sulfides were all located next to $(\mathrm{Fe}, \mathrm{Cr})_{3} \mathrm{O}_{4}$ or accumulated along grain boundaries. Overall, during the $22 \mathrm{~h}$ of reaction time, an approximately $30 \mu \mathrm{m}$ outer scale and an unevenly thick (up to $30 \mu \mathrm{m}$ ) inner corrosion zone formed in dry conditions.

In contrast, the results of the wet experiment (Fig. 2b) showed major differences. The reaction products were homogeneously distributed over the whole scale. No buckling of phases could be seen, and fewer cavities formed. Additionally, here the inner corrosion zone appeared to be more even, with thickness up to $17 \mu \mathrm{m}$, with an outer corrosion zone of about $12 \mu \mathrm{m}$ to $15 \mu \mathrm{m}$. The scale appeared less porous in general compared with the zone formed in dry atmosphere. 

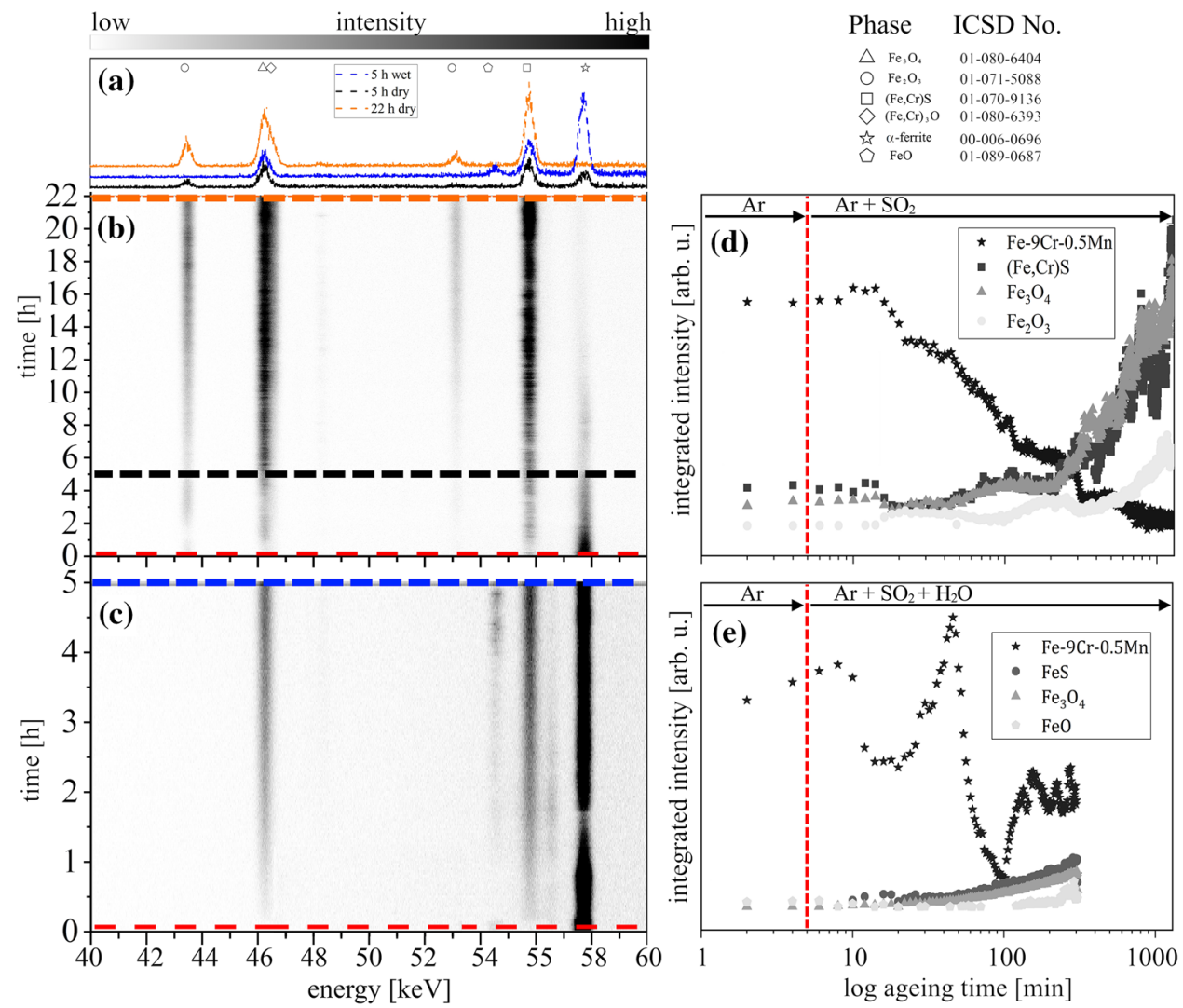

Fig. 1. (a) Single EDXRD pattern with respect to the dashed lines (orange, blue, and black) in pattern in (b) and (c). (b) EDXRD pattern of Fe$9 \mathrm{Cr}-0.5 \mathrm{Mn}$ aged for $22 \mathrm{~h}$ at $650^{\circ} \mathrm{C}$ in $99.5 \% \mathrm{Ar}+0.5 \% \mathrm{SO}_{2}$ atmosphere. Reaction products are indexed above discrete energies in (a). (c) EDXRD pattern of Fe-9Cr-0.5Mn aged for $5 \mathrm{~h}$ at $650^{\circ} \mathrm{C}$ in $69.5 \% \mathrm{Ar}+\sim 30 \% \mathrm{H}_{2} \mathrm{O}+0.5 \% \mathrm{SO}_{2}$ atmosphere. Reaction products are indexed above discrete energies in (a). Extracted integrated intensities of specific reflections as a function of ageing time for (d) dry and (e) wet conditions.

At the gas-scale interface, magnetite $\left(\mathrm{Fe}_{3} \mathrm{O}_{4}\right)$ with decreasing oxygen content in the direction towards the scale-metal interface was found and confirmed by Raman spectroscopy (Supplementary Fig. S3). ( $\mathrm{Fe}, \mathrm{Cr}$ )-sulfides were located between the outer and inner corrosion zone. Below, $(\mathrm{Fe}, \mathrm{Cr})_{3} \mathrm{O}_{4}$ was present. Mn-sulfides could be identified in the inner corrosion zone as small precipitates. Like the observations in dry atmosphere, depletion of $\mathrm{Cr}$ along grain boundaries could be observed.

\section{DISCUSSION}

The results of a real-time study of the early stages of corrosion of Fe-9Cr-0.5Mn in two different hot, $\mathrm{SO}_{2}$-containing atmospheres are presented. The following observations can be summarized:

- After introduction of the reactive atmosphere, sulfides and oxides started to grow simultaneously.

- The external growing oxides were Fe-oxides.

- Cr-containing oxides did not grow outward and were only observed in the inner corrosion zone, beneath the original sample surface.

- Sulfur was only observed at the interface of the outer and inner corrosion zone and accumulated at ferrite grain boundaries.

- The scale morphology differed depending on the experimental atmosphere.

\section{Thermodynamic Boundary Conditions}

The experiments were performed at $650^{\circ} \mathrm{C}$, applying two different gas mixtures. The impurities in $\mathrm{Ar}$ were $\leq 0.5 \mathrm{ppm} / \mathrm{mol}$ for $\mathrm{H}_{2} \mathrm{O}$ and $\leq 0.1 \mathrm{ppm} / \mathrm{mol}$ for $\mathrm{O}_{2}$. The presence of $\mathrm{SO}_{3}$ was neglected for calculation of the conditions in the dry atmosphere. Nevertheless, oxidation of $\mathrm{SO}_{2}$ is thermodynamically possible at temperatures below $1000^{\circ} \mathrm{C}$. It is known that the reaction rate and concentration of $\mathrm{SO}_{3}$ decrease by several orders of magnitude at temperatures above $500^{\circ} \mathrm{C} .{ }^{15,16}$ However, thermodynamic equilibrium calculations using FACTSAGE 7.0 and PS database ${ }^{17}$ show the change in initial gas partial pressure $(\mathrm{Pa})$ for dry and wet conditions at $923 \mathrm{~K}\left(650^{\circ} \mathrm{C}\right)$. To simulate extrema in initial gas equilibria, formation of $\mathrm{SO}_{3}$ was once blocked and once allowed in the calculations (Supplementary Fig. S4). Having a dry atmosphere, the initial gas equilibrium causes formation of $\mathrm{Fe}_{3} \mathrm{O}_{4}$ and $(\mathrm{Fe}$, Cr) $)_{3} \mathrm{O}_{4}$ first. ${ }^{10}$ This behavior changes due to $\mathrm{H}_{2} \mathrm{O}$. Referring to the calculations, in wet atmosphere, 
(a)

Experiment dry $99.5 \%-\mathrm{Ar}+0.5 \%-\mathrm{SO}_{2} 22 \mathrm{~h}$
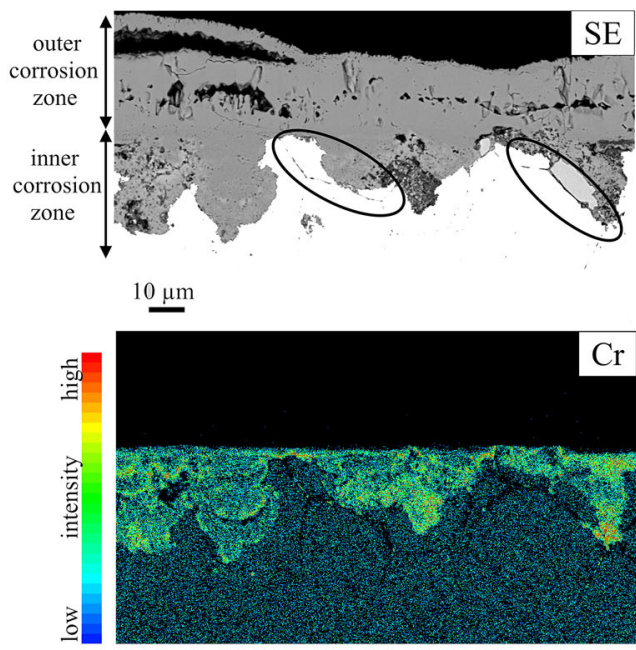
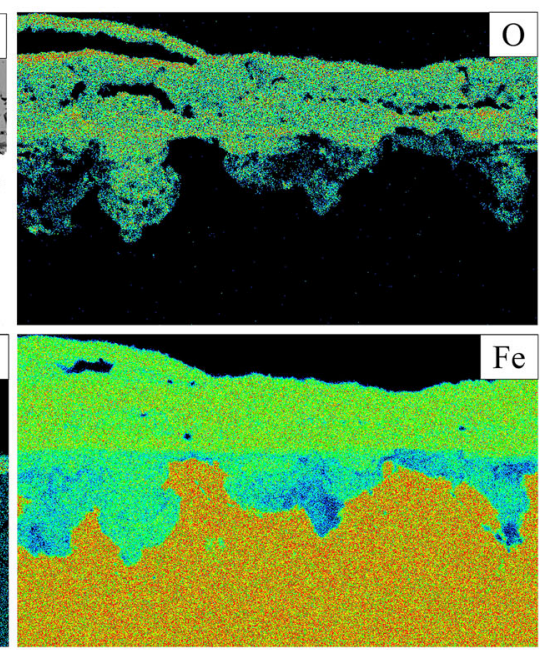
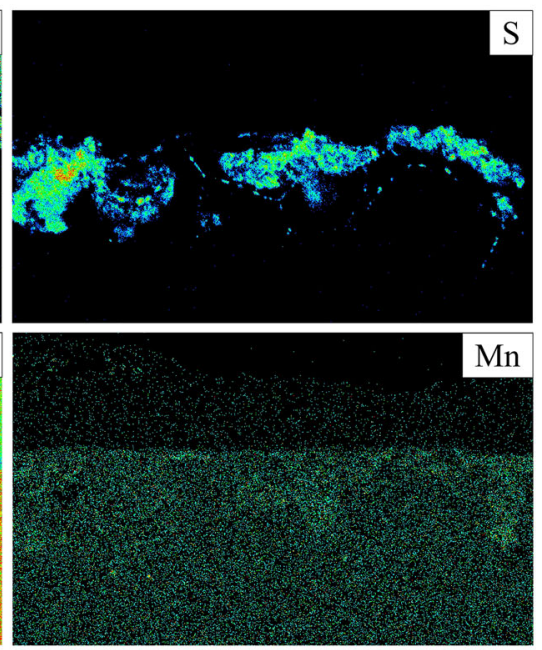

(b)

Experiment wet $69.5 \%-\mathrm{Ar}+0.5 \%-\mathrm{SO}_{2}+30 \%-\mathrm{H}_{2} \mathrm{O} 5 \mathrm{~h}$
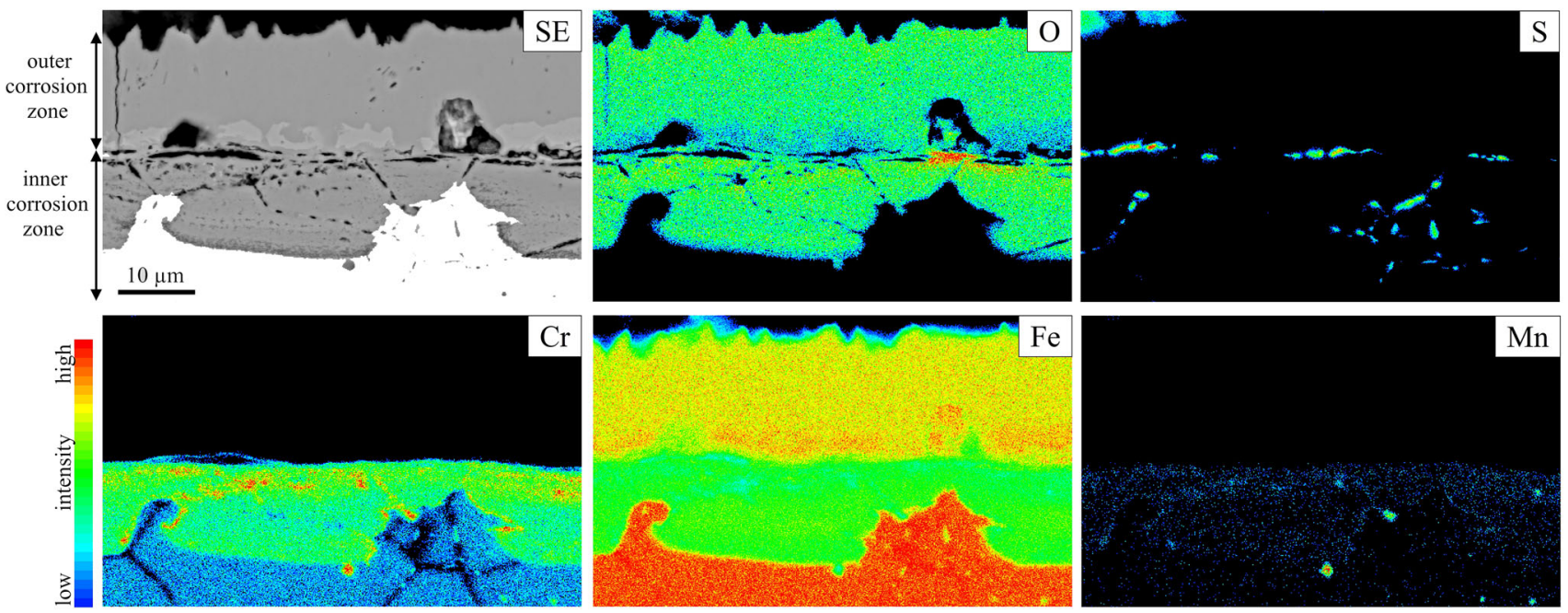

Fig. 2. Secondary-electron (SE) image and element distribution maps ( $\mathrm{Fe}, \mathrm{Cr}, \mathrm{Mn}, \mathrm{S}$, and O) obtained by energy-dispersive x-ray analysis (EDX) of a selected representative region for (a) dry and (b) wet conditions. Ellipses highlight locations of (Fe, Cr)-sulfides in (a).

the stable phases are $\mathrm{Fe}_{2} \mathrm{O}_{3}$ and $(\mathrm{Fe}, \mathrm{Cr})_{3} \mathrm{O}_{4}$. Indeed, the presence of $\mathrm{Fe}_{2} \mathrm{O}_{3}$ was determined only in the dry atmosphere, with increasing oxygen partial pressure at the scale-gas interface. However, the experimental results show $(\mathrm{Fe}, \mathrm{Cr})_{3} \mathrm{O}_{4}$ at the alloyscale interface for both atmospheres. $\mathrm{Fe}_{3} \mathrm{O}_{4}$ was located only above the interface.

\section{Phase Formation at an Early Stage of Corro- sion}

The EDRXD study revealed simultaneous formation of $(\mathrm{Fe}, \mathrm{Cr})_{3} \mathrm{O}_{4}$ and $(\mathrm{Fe}, \mathrm{Cr})$-sulfides with an approximately linear growth rate for the whole experiment for both conditions. This indicates that the following reaction is dominant throughout the experiments:

$$
\begin{aligned}
& \frac{5}{2} \mathrm{Fe}(\mathrm{s})+\mathrm{SO}_{2}(\mathrm{~g}) \rightarrow \mathrm{FeS}(\mathrm{s})+\frac{1}{2} \mathrm{Fe}_{3} \mathrm{O}_{4}(\mathrm{~s}) \\
& \quad \text { with } \Delta G=-215.6 \mathrm{~kJ} \mathrm{~mol}^{-1} \text { at } T=650^{\circ} \mathrm{C}
\end{aligned}
$$

This observation confirms previous results reported after ex situ short-time ageing experiments of pure iron and Fe alloyed with $13 \% \mathrm{Cr}$ by weight exposed to a $0.5 \mathrm{vol} . \% \mathrm{SO}_{2}$-containing atmosphere. ${ }^{18}$ The $\mathrm{Cr}$ content in the model alloy is high enough to stabilize (Fe, $\mathrm{Cr}) \mathrm{S}$. This leads to depletion of the alloy subsurface regions. ${ }^{19}$

In dry conditions, $\mathrm{Fe}_{2} \mathrm{O}_{3}$ started to form, possibly at the expense of $\mathrm{Fe}_{3} \mathrm{O}_{4}$. This was indicated by the observed negative correlation of each compound's integrated intensities with each other, especially 
during the first $300 \mathrm{~min}$. With ongoing reaction time, a higher oxygen content and thus higher oxygen partial pressure were observed at the scalegas interface than within the scale and at the scalealloy interface. An oxygen gradient developed with ongoing gas supply due to the external oxide formation. Magnetite reacts with $\mathrm{SO}_{2}$ to hematite and sulfur according to

$$
\begin{gathered}
2 \mathrm{Fe}_{3} \mathrm{O}_{4}(\mathrm{~s})+\frac{1}{2} \mathrm{SO}_{2}(\mathrm{~g}) \rightarrow 3 \mathrm{Fe}_{2} \mathrm{O}_{3}(\mathrm{~s})+\frac{1}{4} \mathrm{~S}_{2}(\mathrm{~g}) \\
\text { with } \Delta G=-85 \mathrm{~kJ} \mathrm{~mol}^{-1} \text { at } T=650^{\circ} \mathrm{C}
\end{gathered}
$$

The sulfur can further be transported via cracks and pores within the scale towards the scale-alloy interface. The higher sulfur partial pressure at the scale-alloy interface promotes inward growth of metal sulfides.

In wet conditions, the formation of magnetite/ chromite and sulfides was not accompanied by further oxidation to $\mathrm{Fe}_{2} \mathrm{O}_{3}$. $\mathrm{FeO}$ formed instead, connected to a lower $p\left(\mathrm{O}_{2}\right)$ caused by the oxygen gradient throughout the formed oxide scale. Even with water vapor present in the atmosphere, hydroxides should not be stable at the experimental conditions (Supplementary Fig. S4) and could also not be identified throughout the wet experiment. However, the presence of water may lead to formation of $\mathrm{OH}^{-}$and $\mathrm{H}^{+}$ions. While $\mathrm{H}^{+}$can cause protonic defects in the oxide lattice, which changes the microstructure of a scale and thus its diffusion properties, $\mathrm{OH}^{-}$is much smaller than $\mathrm{O}_{2}(0.095 \mathrm{~nm}$ versus $0.140 \mathrm{~nm}$ ), potentially leading to a higher diffusion rate of oxygen through the scale. ${ }^{20}$

\section{$\mathrm{H}_{2} \mathrm{O}$ Effect}

When evaluating the effect of water on the initial corrosion stages in hot $\mathrm{SO}_{2}$ atmospheres, three main differences from the dry conditions could be found:

\section{Oxidation State of Iron Oxides}

The observed reaction products were less oxidized. Measurements showed that the formed magnetite could be divided into well-ordered magnetite and magnetite with oxygen vacancies towards the alloy-scale interface (Supplementary Fig. S3; Fig. 2b). Furthermore, wüstite was observed below the magnetite and confirmed by the 200 reflection observed during the EDXRD experiment and by post experimental XRD analysis. Additionally, no hematite was observed at the scale-gas interface. A plausible reason for all these observations might be that given by Zurek et al., who calculated the decrease in the oxygen partial pressure depending on the presence of $\mathrm{H}_{2}$ in the experimental atmosphere. An equilibrium oxygen $p\left(\mathrm{O}_{2}\right)$ decrease from $10^{-8}$ to $10^{-13}$ is caused by only $1 \mathrm{ppm} \mathrm{H}_{2}$, with important implications for the growth of outer $\mathrm{Fe}_{2} \mathrm{O}_{3} \cdot{ }^{21}$

\section{Scale Thickness}

To achieve comparable signals from the forming corrosion products during in situ EDXRD, the wet experiment was run significantly shorter $(5 \mathrm{~h})$ because of the faster scale growth and to prevent eventual scale spallation. The total scale thickness in the dry conditions after $22 \mathrm{~h}$ was around $60 \mu \mathrm{m}$. The final scale thickness in wet conditions varied between $25 \mu \mathrm{m}$ and $30 \mu \mathrm{m}$ after only $5 \mathrm{~h}$. In the dry experiment, the integrated intensity of the magnetite 311 reflection in EDXRD increased approximately linearly. Hence, the growth rate can be assumed to be constant over the whole runtime. The same can be assumed for the wet experiment for the same reasons. Following this line of reasoning, after $5 \mathrm{~h}$, the dry experiment would only have reached a scale thickness of $14 \mu \mathrm{m}$. This indicates that corrosion rates in wet conditions are twice as fast when compared with dry conditions. Moreover, the loss of the former alloy surface signal is represented by the main $\alpha$-ferrite reflection. ${ }^{10}$ Within the first $150 \mathrm{~min}$, this effect is much more pronounced for the wet than dry atmosphere.

\section{Location of Sulfides}

The experimental time in the dry and wet conditions was different, and the sulfide locations might change with longer experimental time. However, comparison with experiments performed in wet and dry oxyfuel atmosphere shows similar locations for sulfides, even after $1000 \mathrm{~h}$. In our experiments, the sulfides were found along grain boundaries inside the model alloy. Additionally, sulfides were identified inside and partly at the leading tip of the inner corrosion zone in dry conditions. In wet conditions, they were identified only at ferrite grain boundaries and between the outer and inner corrosion zone next to $\mathrm{FeO}$. One possible reason for this might be the denser scale, which may limit sulfur transport through the scale. ${ }^{1}$

\section{CONCLUSION}

EDXRD enables in situ monitoring of reaction product formation on materials in contact with oxidizing and sulfurizing atmospheres, even at high temperatures. $^{22-24}$ According to thermodynamic calculations, several oxides and sulfides are stable in the experimental atmospheres studied here. However, comparing the free enthalpy of oxides and sulfides, oxides are preferred to form first.

Addition of water leads to a significant increase of oxygen diffusion towards the alloy, and thus an increased reaction with the material, followed by material loss. The transport of oxygen into the material, or through the scale, even starts to exceed the supply of oxygen via the supplied atmosphere (formation of $\mathrm{FeO}$ ). This might be explained by the faster diffusion of $\mathrm{OH}^{-}$compared with $\mathrm{O}^{2-}$, as well as potential lattice defects caused by $\mathrm{H}^{+} .{ }^{20}$ 
The inward diffusion of sulfur led to the inner corrosion of both alloys. This effect appeared to be greater under dry conditions. A porous duplex structure was observable on several preferred grains. (Cr, Mn)-sulfide particles at some grain boundaries were observed.

It is possible that the observed S-phases between the inner and outer corrosion zones under wet conditions would start to descend further for longer ageing times. The differences in sulfide location and oxidation state would then be an effect mainly based on increased oxygen diffusion.

\section{ACKNOWLEDGEMENTS}

The authors would like to acknowledge Romeo Saliwan Neumann for SEM analysis, Artur Goebel for the experimental setup, Helmholtz-Zentrum Berlin for the allocation of synchrotron beamtime at BESSY II, and Manuela Klaus and Christoph Genzel for their assistance during the experiments and various valuable discussions.

\section{OPEN ACCESS}

This article is distributed under the terms of the Creative Commons Attribution 4.0 International License (http://creativecommons.org/licenses/by/4.0/ ), which permits unrestricted use, distribution, and reproduction in any medium, provided you give appropriate credit to the original author(s) and the source, provide a link to the Creative Commons license, and indicate if changes were made.

\section{ELECTRONIC SUPPLEMENTARY MATERIAL}

The online version of this article (https://doi.org/ 10.1007/s11837-019-03335-9) contains supplementary material, which is available to authorized users.

\section{REFERENCES}

1. K. Chandra, A. Kranzmann, R.S. Neumann, and F. Rizzo, Oxid. Met. 84, 463 (2015).

2. J.P. Abellan, T. Olszewski, H.J. Penkalla, G.H. Meier, L. Singheiser, and W.J. Quadakkers, Mater. High Temp. 26, 63 (2009).

3. R. Viswanathan, J. Sarver, and J.M. Tanzosh, J. Mater. Eng. Perform. 15, 255 (2006).

4. F. Gesmundo, C.D. Asmundis, S. Merlo, and C. Bottino, Werkst. Korros. 30, 179 (1979).

5. A. Kranzmann, T. Neddemeyer, A.S. Ruhl, D. Huenert, D. Bettge, G. Oder, and R.S. Neumann, Int. J. Greenh. Gas Control 5, S168 (2011).

6. N. Birks, G.H. Meier, and F.S. Pettit, Introduction to the High-Temperature Oxidation of Metals (Cambridge: Cambridge University Press, 2006).

7. J. Gilewicz-Welter, Oxid. Met. 11, 81 (1977).

8. P. Huczkowski, T. Olszewski, M. Schiek, B. Lutz, G.R. Holcomb, V. Shemet, W. Nowak, G.H. Meier, L. Singheiser, and W.J. Quadakkers, Mater. Corros. 65, 121 (2014).

9. N.K. Othman, N. Othman, J. Zhang, and D.J. Young, Corros. Sci. 51, 3039 (2009)

10. C. Stephan-Scherb, K. Nützmann, A. Kranzmann, M. Klaus, and C. Genzel, Mater. Corros. 69, 678 (2018).

11. S. Schorr, C. Stephan, R. Mainz, H. Rodriguez-Alvarez, and M. Tovar, Adv. Eng. Mater. 13, 737 (2011).

12. Online document: ICSD-Fiz-Karlsruhe Inorganic crystal structure database. (2008), http://icsdweb.fiz-karlsruhe.de. Accessed 21 Feb 2018.

13. C. Genzel, I.A. Denks, J. Gibmeier, M. Klaus, and G. Wagener, Nucl. Instrum. Methods Phys. Res. Sect. A 578, 23 (2007).

14. T. Laetsch and R.T. Downs, Abstracts from the 19th General Meeting of the International Mineralogical Association, p. 23 (2006).

15. D. Fleig, F. Normann, K. Andersson, K. Johnsson, and B. Leckner, Energy Procedia 1, 383 (2009).

16. L.P. Belo, L.K. Elliott, R.J. Stanger, R. Spörl, K.V. Shah, J. Maier, and T.F. Wall, Energy Fuels 28, 7243 (2014).

17. Online document: FactSage 7.0 (2017), http://www.factsa ge.com/. Accessed 21 Feb 2018.

18. K. Nützmann, A. Kranzmann, and C. Stephan-Scherb, Mater. High Temp. 209, 1 (2018).

19. D.J. Young, Elsevier Sci. 1, 1 (2008).

20. N.H. Nickel and I. Sieber, Appl. Phys. Lett. 72, 2683 (1998).

21. J. Zurek, M. Michalik, F. Schmitz, T.U. Kern, L. Singheiser, and W.J. Quadakkers, Oxid. Met. 63, 401 (2005).

22. R. Mientus and K. Ellmer, Surf. Coat. Technol. 142, 748 (2001).

23. M. Rehan, G.M. Kale, and X.J. Lai, CrystEngComm 17, 2013 (2015).

24. J. Schulte, S. Brunken, and K. Ellmer, J. Cryst. Growth 384, 114 (2013). 